\title{
A STUDY TO ASSESS THE ASSOCIATION BETWEEN SERUM NEOPTERIN LEVELS AND VARIOUS BIOCHEMICAL, CLINICAL, AND ECHOCARDIOGRAPHIC VARIABLES
}

\author{
Srivatsan Elayalwar', Jayaprada Lakshmipathi \\ ${ }^{1}$ Assistant Professor, Department of Biochemistry, KAPV Government Medical College, Periyamilaguparai, Trichy, Tamilnadu. \\ ${ }^{2}$ Associate Professor and HOD, Department of Nutrition and Dietetics, Seethalakshmi Ramaswami College, Tiruchirappalli, Tamilnadu.
}

\section{ABSTRACT}

\section{BACKGROUND}

Serum neopterin, an immune modulator secreted by activated macrophages is found to be increased in AMI as inflammatory marker. The present study assessed the association between serum neopterin levels and various biochemical and clinical factors.

\section{MATERIALS AND METHODS}

Patients with increased levels of serum neopterin were selected and the association with various enzyme markers, LVEF, age, gender, hypertension, diabetes mellitus, and hypercholesterolemia was analysed in the study.

\section{RESULTS}

At the end of the study, it is found statistically significant association between high levels of serum neopterin and factors like enzyme markers, echo findings, and increase in age.

\section{CONCLUSION}

From the study, it can be concluded that there is significant correlation between high levels of serum neopterin and CKMB, an enzyme marker in AMI. High sensitive CRP was also significantly associated with high levels of serum neopterin. According to the echo findings, LVEF is recorded as low in the study group. Hence, based on the statistical data, the above factors can be considered as independent predictors of the levels of serum neopterin. Based on the age group of the study group, patients in the increasing age group were found to be significantly associated with high levels of serum neopterin and hence increasing age group can also be included as one of the independent predictors of high serum neopterin levels. The other variables like hypertension, diabetes mellitus, and hypercholesterolemia are not associated significantly. Recent studies indicate that HMG-CoA reductase inhibitors have anti-inflammatory properties in addition to lipid lowering properties. This finding suggest that the lower serum neopterin levels in patients who were on statin treatment maybe a marker of the beneficial effects of these pharmacological agents an monocyte/macrophage function.

\section{KEYWORDS}

High Serum Neopterin Levels, High Levels of Enzyme Markers, High Sensitive CRP, LVEF, Increasing Age Group, Independent Predictors.

HOW TO CITE THIS ARTICLE: Elayalwar S, Lakshmipathi J. A study to assess the association between serum neopterin levels and various biochemical, clinical, and echocardiographic variables. J. Evolution Med. Dent. Sci. 2016;5(57):3890-3893, DOI: $10.14260 /$ jemds/2016/891

\section{INTRODUCTION}

AMI is one of the medical emergencies, which may lead to death if not diagnosed and treated in time. Clinically, AMI present with severe chest pain, dyspnoea, palpitation, profuse sweating leading to cardiac arrhythmias, cardiogenic shock, cardiac failure, and death. Biochemically, there are many markers like CK-MB, LDH, troponin, high-sensitive CRP, and so on. Electrocardiography (ECG) and echocardiography are the diagnostic tools for confirming AMI. Apart from these, there are many newer biomarkers like neopterin, IMI (Ischemia Modified Albumin), serum level of pentraxins 3, and so on. The incidence of AMI strongly correlates with genetic and

Financial or Other, Competing Interest: None.

Submission 09-06-2016, Peer Review 04-07-2016,

Acceptance 09-07-2016, Published 15-07-2016.

Corresponding Author:

Dr. Srivatsan Elayalwar,

Assistant Profesor,

Department of Biochemistry,

KAPV Government Medical College,

Periyamilaguparai, Trichy,

Tamilnadu, India.

E-mail: drsrivatsantrichy@gmail.com

DOI: $10.14260 /$ jemds/2016/891 behavioural pre-disposition to atherosclerosis. Inflammation plays important role in the pathogenesis of atherosclerosis. Atherosclerosis is a chronic inflammatory and healing response of the arterial wall due to endothelial injury. This endothelial injury produces dysfunction, increased vascular permeability, leucocyte adhesion, and thrombosis. There will be accumulation of lipoproteins mainly LDL in oxidised form in the vessel wall. Next, monocyte adhesion to the endothelium occurs and formation of foam cells. There will be platelet adhesion. Subsequent migration of inflammatory cells into the subendothelial space requires chemotaxis controlled by chemokines induced by cytokines. Mononuclear cells within this initial filtrate as well as intrinsic vascular cells subsequently release growth factors that stimulate proliferation of smooth cells and hence progression of plaque. This atheromatous plaque is prone to rupture by proinflammatory cytokines due to activation of monocytes and macrophages and is reflected by the high levels of biomarkers. The new novel biomarker neopterin is a useful tool to monitor monocyte macrophage activity in AMI. The serum levels of neopterin is taken for the present study, which has high significant correlation in AMI with complications. In 
the present study, the assessment of association between neopterin level and other biomarkers, clinical features, ECG findings, echo findings are made. Neopterin was first isolated from larvae of bee in 1963. Eventually, neopterin was identified as the fluorescent component that was elevated in the urine of mice with Ehrlich ascites tumour. Now, it is proved that this is the exclusive product of monocytes/macrophages that have been stimulated by interferon gamma, a cytokine that is produced by activated T-lymphocytes and nature killer cells.(1) Biochemically, neopterin belongs to pteridines group. It is a catabolic product of guanosine triphosphate [GTP]. Its molecular formula is $\mathrm{C}_{9} \mathrm{H}_{11} \mathrm{~N}_{5} \mathrm{O}_{4}$. Its molecular mass is 253.215 . Neopterin is synthesised from GTP via GTP cyclohydrolase (GTP-CH). The activity of GTP-CH can be greatly enhanced by interferon gamma. 7,8-dihydroneopterin triphosphate ( $\left.\mathrm{NH}_{2} \mathrm{TP}\right)$ is on the biosynthetic pathway of $5,6,7,8$ tetrahydrobiopterin $\left(\mathrm{BH}_{4}\right) . \mathrm{BH}_{4}$ represents the electron donor in the amino acid metabolic pathways. Human monocytes/macrophages lack the enzyme 6-pyruvoyl-tetrahydrobiopterin synthase, which converts $\mathrm{NH}_{2} \mathrm{TP}$ to 6pyruvoyl-tetra-hydrobiopterin. Thus, in these cells, $\mathrm{NH}_{2} \mathrm{TP}$ accumulates and after hydrolysis by phosphatases is excreted as dihydroneopterin or neopterin. Neopterin reflects the monocytes/macrophages activity stimulated by interferon gamma, a cytokine that is produced by the activated $\mathrm{T}$ lymphocytes, the nature killer cells. Estimation of serum levels of neopterin is a new novel biomarker in AMI and seems to be a prognostic marker for MACE (Massive Adverse Cardiac Events) in AMI.(2) Atherosclerosis is a complex disease that involves lipoprotein influx and modification increased prooxidant stress and inflammatory angiogenic and fibroproliferative responses intermingled with extra cellular matrix and smooth muscle cell proliferation resulting in the formation of atherosclerotic plaque.(3) The concept of response to injury, hypothesis considers atherosclerosis as a chronic inflammatory response of the arterial wall to the injured endothelium. Inflammation plays important role in the pathogenesis of atherosclerosis. Atherosclerosis remains the major cause of death and premature disability in the developed countries. Formation of fatty streak, the earliest phase of atherogenesis involves recruitment of leucocytes due to expression of leucocyte adhesion molecule on endothelial cells in turn triggered by primary proinflammatory cytokines(4). Subsequent migration of inflammatory cells into the subendothelial space requires chemotaxis controlled by chemokines induced by the primary cytokines. Mononuclear cells within this initial infiltrate as well as intrinsic vascular cells subsequently release growth factors that stimulate proliferation of smooth muscle cells and hence the progression of plaques. Inflammation is a major feature of atherothrombosis and there is growing evidence of an association between systemic inflammation and the occurrence of stroke, peripheral artery disease, unstable angina, and IHD. Such an inflammatory component may be the final common result of a variety of infectious and noninfectious inflammatory stimuli and of the individual immunologic and inflammatory response. Triggers of plaque rupture and novel risk factors for ACS are: Neopterin, Lselectin, Macrophage inflammatory peptide, Interleukin, Intracellular Adhesion, Vascular Cell Adhesion, Leucocyte Count, Heat Shock Proteins, Matrix metalloproteinase 9 (MMMP 9).(5) Inflammation plays a role in the pathogenesis
IHD. It is now accepted that inflammatory processes takes place within the atheromatous lesions and significantly contribute to the progression of stenosis and acute coronary events. Studies have shown an association between markers of inflammation and the presence of coronary atherosclerosis as well as the exacerbation of inflammation during acute myocardial ischaemia.(6) Several inflammatory markers have been shown to represent true cardiovascular risk factors. In this respect, the CRP, the neopterin, and the leucocyte count are all of particular interest. Studies suggest that high levels of serum neopterin maybe a marker of atheromatous plaque vulnerability and identify patients at increased risk of serious coronary events. The results of these studies reveal that neopterin may be a marker of coronary disease activity rather than a marker of presence of CAD. Inflammation plays a vital role in atherosclerosis and coronary heart disease. Inflammatory processes of the coronary arterial wall are involved in plaque formation, progression, and finally plaque instability leading to clinical manifestations of stable coronary artery disease and acute coronary syndromes. Biomarkers of inflammation emerged as potentially useful tools for risk stratification.

Elevated serum levels of neopterin, an immune modulator secreted by activated macrophages with patients in ACS(7). Serum neopterin is an independent predictor of MACE in patients with ACS.(8) This marker of macrophage maybe useful for risk stratification in patients with AMI. Clinical studies performed recently proved great role of inflammatory processes in development of atherosclerosis. These inflammatory biomarkers are used in the diagnosis and identification of patients with unstable angina pectoris and myocardial infarct.

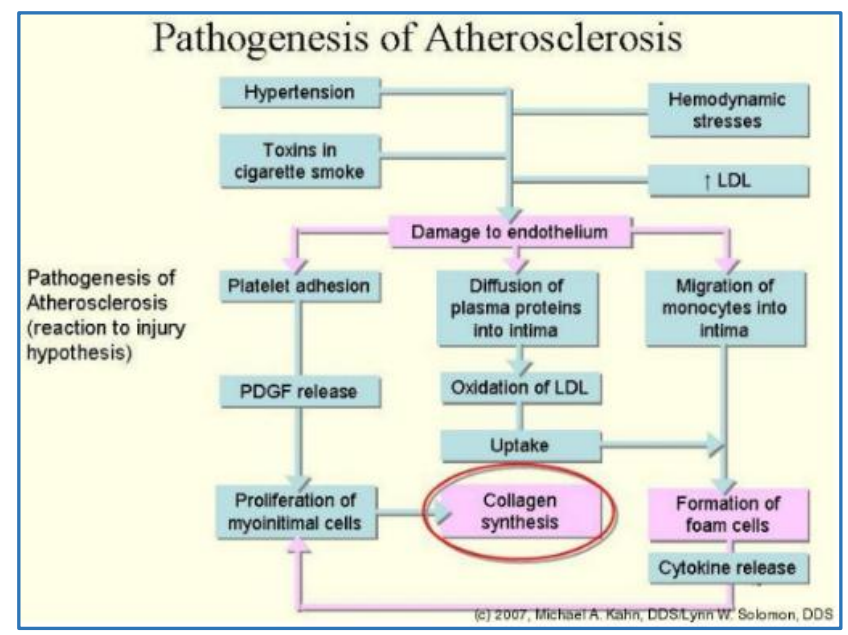

Neopterin stimulates nuclear factor-kB translocation to the nucleus promoting the expression of proinflammatory genes, adhesion molecules, tissue factor, and other substances implicated in the inflammatory processes that take place within the arterial wall in atherogenesis and atheromatous plaque disruption.

\section{MATERIALS AND METHODS}

Neopterin is an activation marker for monocytes/macrophages and its circulating levels in the serum is considered to be one of the prognostic markers in the treatment of AMI.(9) 


\section{Inclusion Criteria}

All cases admitted in the ICCU with the clinical features of AMI and with the positive documentation like increased cardiac enzyme levels, high-sensitive CRP, ECG findings, ECHO findings, etc. The group of patients in the age group between 45-65 years were selected irrespective of the gender difference. The associated findings like hypertension, diabetes mellitus, and hypercholesterolemia were also included in the study. Patients with acute symptoms only were selected irrespective of time of admission.

\section{Exclusion Criteria}

Patients with features of tuberculosis lesions, with features of atypical chest pain, with features of HIV infection, with the history of recent renal transplantation were also given high levels of serum neopterin. Hence, the above-mentioned noncardiac causes were excluded for the study. The present study is the estimation of the serum neopterin in patients with AMI and its association with various variables. To start with the study, a protocol was framed with inclusion, exclusion criteria, aims and objectives, materials and methods, and with the review of literatures and references taken from various international journals and from the prescribed Text Books of Cardiology (Harrison's Text Book of Medicine, Braunwald's Heart Disease). For this study, 40 patients were selected as study group and 40 patients were selected as control group based on the inclusion/exclusion criteria. The study group were collected from the ICCU Department of Cardiology. The blood samples of the study group were properly stored in the deep freezer after perfect centrifugation. The blood samples of the control group were collected from the normal persons and after perfect centrifugation and they were stored in the deep freezer. During collection, the usual precautions for venepuncture were observed. The grossly haemolytic, icteric, and lipemic samples were discarded. Samples were centrifuged again before assay to remove any particulate material. The quantitative estimation of serum neopterin was done using neopterin, ELISA-Enzyme-linked Immunosorbent Assay for the In Vitro Diagnostic Quantitative Determination of Serum Neopterin obtained from IBL International.(10)

\section{Quantitative Determination of Serum Neopterin}

Solid phase Enzyme-Linked Immunosorbent Assay (ELISA) based on the basic principle of a competitive ELISA. An unknown amount of antigen in the sample and a fixed amount of enzyme labelled antigen compete for the antibody binding sites (Rabbit-anti-neopterin). Both antigen-antibody complexes bind to the wells of the Microtiter strips coated with a goat-anti-rabbit antibody. Unbound antigen is removed by washing. The intensity of the colour developed after the substrate incubation is inversely proportional to the amount of antigen in the sample. Quantitative Determination of CReactive Protein (CRP): The CRP ultrasensitive is a quantitative turbidimetric test for the measurement of low levels of C-reactive protein in a human serum or plasma. Quantitative determination of C-Kinase $\mathrm{Mb}$ : Principle: Immunoinhibition Method: Principle: Specific Antibodies against CK-M inhibit the complete CKMM activity and the CKM subunit of CK-MB. Only CKB activity is measured. The rate of increase in absorbance is measured and is directly proportional to enzyme activity. Damage to the myocardium will occur in acute myocardial infarction will result in increased circulating levels of CK-MB isoform. Quantitative determination of blood glucose was done by glucose oxidase/peroxidase method. Quantitative determination of serum HDL cholesterol was done by enzymatic colorimetric method for HDL cholesterol. Quantitative determination of total cholesterol was done by enzymatic cholesterol esterase method. Quantitative determination of triglycerides was done by enzymatic colorimetric method.

Quantitative Determination of Very Low-Density Lipoproteins and Low-Density Lipoproteins.

- Very Low-Density Lipoproteins=triglycerides $/ 5$.

- Low-Density Lipoprotein=Total cholesterol-[HDL+VLDL].

\begin{tabular}{|c|c|c|}
\hline $\begin{array}{l}\text { Levels of Serum } \\
\text { Neopterin }\end{array}$ & Variables & P Value \\
\hline $\begin{array}{l}\text { High Levels of } \\
\text { Serum } \\
\text { Neopterin } \\
\end{array}$ & Advancing Age & $\begin{array}{l}\text { Highly Significant } \\
(\mathrm{P}<0.000<0.05)\end{array}$ \\
\hline $\begin{array}{l}\text { High Levels of } \\
\text { Serum } \\
\text { Neopterin }\end{array}$ & High CK-MB & $\begin{array}{l}\text { Highly Significant } \\
(\mathrm{P}<0.000<0.05)\end{array}$ \\
\hline $\begin{array}{l}\text { High levels of } \\
\text { Serum } \\
\text { Neopterin }\end{array}$ & $\begin{array}{l}\text { Increased High } \\
\text { Sensitive CRP }\end{array}$ & $\begin{array}{l}\text { Highly Significant } \\
(\mathrm{P}<0.000<0.05)\end{array}$ \\
\hline $\begin{array}{l}\text { High Levels of } \\
\text { Serum } \\
\text { Neopterin }\end{array}$ & $\begin{array}{c}\text { Decreased Left } \\
\text { Ventricular } \\
\text { Ejection Fraction } \\
\text { (LVEF) }\end{array}$ & $\begin{array}{l}\text { Highly Significant } \\
(\mathrm{P}<0.000<0.05)\end{array}$ \\
\hline $\begin{array}{l}\text { High Levels of } \\
\text { Serum } \\
\text { Neopterin }\end{array}$ & $\begin{array}{l}\text { Systolic Blood } \\
\text { Pressure }\end{array}$ & $\begin{array}{l}\text { Not Significant } \\
\qquad(\mathrm{P}>0.05)\end{array}$ \\
\hline $\begin{array}{l}\text { High Levels of } \\
\text { Serum } \\
\text { Neopterin }\end{array}$ & $\begin{array}{l}\text { Diastolic Blood } \\
\text { Pressure }\end{array}$ & $\begin{array}{l}\text { Not Significant } \\
\quad(P>0.05)\end{array}$ \\
\hline $\begin{array}{l}\text { High levels of } \\
\text { serum } \\
\text { Neopterin } \\
\end{array}$ & Blood Glucose & $\begin{array}{l}\text { Not Significant } \\
\quad(P>0.05)\end{array}$ \\
\hline $\begin{array}{l}\text { High Levels of } \\
\text { Serum } \\
\text { Neopterin }\end{array}$ & Total Cholesterol & $\begin{array}{l}\text { Not Significant } \\
\qquad(\mathrm{P}>0.05)\end{array}$ \\
\hline $\begin{array}{l}\text { High Levels of } \\
\text { Serum } \\
\text { Neopterin } \\
\end{array}$ & $\begin{array}{c}\text { High Density } \\
\text { Lipoprotein (HDL) }\end{array}$ & $\begin{array}{l}\text { Not Significant } \\
\quad(P>0.05)\end{array}$ \\
\hline $\begin{array}{l}\text { High levels of } \\
\text { serum } \\
\text { Neopterin }\end{array}$ & $\begin{array}{c}\text { Low Density } \\
\text { Lipoprotein(LDL) }\end{array}$ & $\begin{array}{l}\text { Not Significant } \\
\qquad(\mathrm{P}>0.05)\end{array}$ \\
\hline $\begin{array}{l}\text { High Levels of } \\
\text { Serum } \\
\text { Neopterin }\end{array}$ & $\begin{array}{c}\text { Serum } \\
\text { Triglycerides }\end{array}$ & $\begin{array}{l}\text { Not Significant } \\
\quad(\mathrm{P}>0.05)\end{array}$ \\
\hline $\begin{array}{l}\text { High Levels of } \\
\text { Serum } \\
\text { Neopterin }\end{array}$ & $\begin{array}{l}\text { Previous History } \\
\text { of Hospitalisation }\end{array}$ & $\begin{array}{l}\text { Not Significant } \\
\quad(\mathrm{P}>0.05)\end{array}$ \\
\hline $\begin{array}{l}\text { High Levels of } \\
\text { Serum } \\
\text { Neopterin } \\
\end{array}$ & $\begin{array}{l}\text { Patients with Typical } \\
\text { Clinical Symptoms }\end{array}$ & $\begin{array}{l}\text { Not Significant } \\
\quad(\mathrm{P}>0.05)\end{array}$ \\
\hline
\end{tabular}

\section{RESULTS}

In the study, high levels of serum neopterin was correlated statistically with variables like age, gender, cardiac enzymes, CKMB, high-sensitive CRP, hypertension, diabetes mellitus, 
hypercholesterolemia, Low-Density Lipoprotein (LDL), HighDensity Lipoprotein(HDL), Left Ventricular Ejection Fraction (LVEF). From the data obtained, it is proved that high levels of serum neopterin is correlated significantly with increasing age $(\mathrm{P}<0.000<0.05)$ with respect to high sensitive CRP. It is proved that high levels of serum neopterin has significant association $(\mathrm{P}<0.000<0.05)$. Serum CK-MB levels are also having significant correlation with serum neopterin levels $(\mathrm{P}<0.000<0.05)$. Apart from this, serum neopterin levels have significant correlation with left ventricular function by assessing left ventricular ejection fraction using Electrocardiography (ECG) and Echocardiography. The $P$ value is found to be $(\mathrm{P}<0.000<0.05)$. The serum neopterin levels are associated statistically with other variables like systolic blood pressure, diastolic blood pressure, fasting blood glucose, Low-Density Lipoprotein (LDL) level, High-Density Lipoprotein (HDL) levels, and the results obtained are not statistically significant $P$ value more than 0.05 . The serum levels of neopterin is associated with patients with the history of previous hospitalisation and it is not statistically significant $[\mathrm{P}>0.05]$. The high levels of serum neopterin are also associated with patients with typical symptoms of AMI and statistical significance was not proved [ $\mathrm{P}>0.05]$.

\section{LIMITATIONS}

Relatively small size of the study group is one of the limitation of the study. Even with the small size of the study group, there is significant correlation statistically. The association between serum neopterin levels and the pharmacological effects of various drugs like antihypertensive drugs, lipid-lowering drugs, and oral hypoglycaemic drugs was not done in the present study due to lack of follow up. Hence, follow up of the study may be needed for the further research work. Moreover, the high level of serum Neopterin was not correlated with other new biomarkers like troponin, etc.

\section{DISCUSSION}

From the study, various clinical, biochemical, and echocardiographic variables were correlated with high levels of serum neopterin. According to statistical analysis, the biomarkers like CK-MB, high-sensitive CRP are having highly significant correlation with high levels of serum neopterin. Echocardiographic studies reveal that low left ventricular ejection fraction is having significant correlation with high levels of serum neopterin. Apart from this, increase in age is also having significant correlation with high levels of serum neopterin. But, the parameters like hypertension, diabetes mellitus, hypercholesterolemia, history of previous hospitalisation, history of typical symptoms of AMI are not having significant correlation with high levels of serum neopterin. Hence, the variables like increasing in age, high levels of CK-MB, high levels of high-sensitive CRP, and low left ventricular ejection fraction are having high correlation with high levels of serum neopterin and hence these variables may be included for risk stratification in acute myocardial infarction. As high levels of serum neopterin is having significant correlation with occurrence of adverse events in acute myocardial infarction, the variables like high CK-MB, high-sensitive CRP, low left ventricular ejection fraction, and increasing in age of the patients can also be correlated with occurrence of adverse events in acute myocardial infarction.

\section{CONCLUSION}

Hence to conclude from the above study as high levels of serum neopterin are associated significantly with high levels of CK$M B$, increased high-sensitive CRP levels, decreased left ventricular ejection fraction, and increase in the age group of the patients. Thus, the above-mentioned variables can be considered as independent predictors of serum levels of neopterin to assess risk stratification in acute myocardial infarction.

\section{REFERENCES}

1. Alber HF, Duftner C, Schek WM, et al. Neopterin, CD4+cd28- lymphocytes extent and severity of coronary artery disease. Int J Cardiol 2009;135(1):27-35.

2. Auer J, Berent R, Lassnig E, et al. Prognostic significance of immune activation after acute coronary syndromes. Journal of the American College of Cardiology 2002;39(11):1878.

3. Fuster V, Badimon L, Badimon JJ, et al. The pathogenesis of coronary artery disease and the acute coronary syndromes (2). N Engl J Med 1992;326(5):310-8.

4. Schumacher M, Eber B, Tatzber F, et al. Neopterin levels in patients with coronary artery disease. Atherosclerosis 1992;94(1):87-8.

5. Hermus L, Schuitemaker JHN, Tio RA, et al. Novel serum biomarkers in carotid artery stenosis: useful to identify the vulnerable plaque? Clinical Biochemistry 2011;44(16):1292-8.

6. Schumacher M, Halwachs G, Tatzber F, et al. Increased neopterin in patients with chronic and acute coronary syndromes. Journal of the American College of Cardiology 1997;30(3):703-7.

7. Tatzber F, Rabl H, Koriska K. Elevated serum neopterin levels in atherosclerosis. Atherosclerosis 1991;89(23):203-8.

8. Weiss G, Willeit J, Kiechl S, et al. Increased concentrations of neopterin in carotid atherosclerosis. Atherosclerosis 1994;106(2):263-71.

9. Gupta S, Fredericks S, Schwartzman RA, et al. Serum neopterin in acute coronary syndromes. Lancet 1997;349(9060):1252-3.

10. Wachter H, Fuchs D, Hausen A, et al. Neopterin. Biochemistry methods clinical application. Berlin: DeGruyter 1992;10(4):289. 